\title{
Community-level consequences of mycorrhizae depend on phosphorus availability
}

\author{
Cathy D. Collins ${ }^{1}$ and Bryan L. Foster \\ 1200 Sunnyside Avenue, Haworth Hall, University of Kansas, Lawrence, Kansas 66045 USA
}

\begin{abstract}
In grasslands, arbuscular mycorrhizal fungi (AMF) mediate plant diversity; whether AMF increase or decrease diversity depends on the relative mycotrophy in dominant vs. subordinate plants. In this study we investigated whether soil nutrient levels also influence the ability of AMF to mediate plant species coexistence. First, we developed a conceptual model that predicts the influence of AMF on diversity along a soil nutrient gradient for plant communities dominated by mycotrophic and non-mycotrophic species. To test these predictions, we manipulated phosphorus to create a soil nutrient gradient for mesocosm communities composed of native prairie grasses and then compared community properties for mesocosms with and without AMF. We found that, where $\mathrm{P}$ was limiting, AMF increased plant diversity and productivity, and also altered community structure; however, at high P, AMF had little influence on aboveground communities. Compositional differences among treatments were due largely to a trade-off in the relative abundance of $\mathrm{C}_{3}$ vs. $\mathrm{C}_{4}$ species. Our study emphasizes how environmental constraints on mutualisms may govern community- and ecosystem-level properties.
\end{abstract}

Key words: arbuscular mycorrhizal fungi, AMF; $C_{3}$ vs. $C_{4}$ species; Kansas, USA; mesocosm; mycorrhizae; nutrient gradient; $P$ limitation; perennial native grasses; plant diversity; plant-fungal symbioses; soil ecology; tallgrass prairie.

\section{INTRODUCTION}

Identifying factors that generate and maintain plant diversity and productivity remains one of the central goals of ecology. Until recently, microbes have been largely ignored as drivers of plant community dynamics (Reynolds et al. 2003, Wardle et al. 2004). Given their pivotal role in nutrient cycling and nutrient transfer, microbes are gaining attention as key players in ecosystem processes (van der Heijden et al. 2008) and the crucial role they may play in mediating plant response to global changes (Johnson et al. 2003b, Tylianakis et al. 2008). Human-induced global changes such as nutrient deposition alter the environmental context for species interactions. In order to predict the aboveground consequences of altering soil environments, we must account for biotic interactions belowground, such as the symbiosis between plants and mycorrhizae. We know little about how the changing abiotic environment shapes microbial influences on plant communities (Bever 2003, van der Heijden et al. 2008). In this paper, we examine how soil nutrient levels impact plant-fungal symbioses and, ultimately, plant community diversity and productivity.

Arbuscular mycorrhizal fungi (AMF) are soil organisms that colonize most terrestrial plant species (Smith

Manuscript received 20 August 2008; revised 8 December 2008; accepted 7 January 2009. Corresponding Editor: J. N. Klironomos.

${ }^{1}$ E-mail: cathy.collins@wustl.edu and Read 1997). This symbiosis is typically considered mutualistic because the fungus provides soil resources, particularly phosphorus, to the plant, and receives photosynthate in return (Smith and Read 1997). However, environmental conditions can alter the costs and benefits of the AMF-plant symbiosis along the spectrum of mutualism to parasitism (Johnson et al. 1997). For instance, high-phosphorus environments may eliminate resource limitation in such a way that AMF impose a carbon drain on plants, depressing plant growth (Koide 1991, Johnson et al. 1997). Independent of soil nutrient status, not all plants benefit equally from AMF symbioses. Reliance on AMF for optimal growth varies among plant species (Klironomos 2003), plant functional groups (Wilson and Hartnett 1998), and plants characteristic of different successional stages (Janos 1980). Given the significant role AMF play in plant resource acquisition, together with observed variation among plant species in the benefits derived from AMF colonization, it is no surprise that AMFmediated competition contributes to grassland plant community diversity (van der Heijden 2002).

AMF affect plant diversity positively or negatively, depending on the degree to which the dominant plant species depend on AMF (Hartnett and Wilson 2002, Urcelay and Diaz 2003). When the competitively subordinate plants derive substantial growth benefits from hosting AMF, the presence of AMF increases diversity (e.g., Grime et al. 1987, van der Heijden et al. 1998). By contrast, AMF decrease diversity when AMF 
disproportionately enhance growth in dominant plants (e.g., Hartnett and Wilson 1999, O'Connor et al. 2002). In Kansas tallgrass prairie, for instance, co-occurring warm-season $\left(\mathrm{C}_{4}\right)$ and cool-season $\left(\mathrm{C}_{3}\right)$ grasses and forbs vary in their dependence on AMF; the dominant grasses are $\mathrm{C}_{4}$ and rely on AMF for optimal growth (Wilson and Hartnett 1998). Suppressing AMF results in competitive release of many subordinate $\mathrm{C}_{3}$ grass and forb species that rely less (or not at all) on AMF (Hartnett and Wilson 1999). Additionally, AMF can influence ecosystem function both directly and indirectly. In nutrient-deficient substrates, the presence of AMF increases primary productivity directly through nutrient acquisition and enhanced photosynthesis (Smith and Read 1997). When AMF increase plant diversity, this, in turn, may increase plant productivity indirectly by enhancing plant complimentarity and community-wide resource-use efficiency (Klironomos et al. 2000, van der Heijden 2002).

Competition for nutrients plays a major role in governing grassland plant community dynamics (Tilman 1982). Adding a single nutrient alters the absolute abundance of that nutrient, as well as its abundance relative to other nutrients (e.g., $\mathrm{N}: \mathrm{P}$ ), often shifting the identity of the limiting nutrients and ultimately plant community composition (Tilman 1985). For instance, enriching soils with $\mathrm{N}$ favors $\mathrm{N}$-limited species, and increases plant productivity at the expense of diversity (Tilman 1987, Foster and Gross 1998). To the extent that AMF mediate competition via nutrient acquisition, anthropogenic inputs of $\mathrm{N}$ and $\mathrm{P}$ will influence the role AMF play in mediating plant-species coexistence. Indeed, pairwise studies have shown that AMF and soil nutrient levels interact to determine the competitive "winner" among plant species (Hartnett et al. 1993, Daleo et al. 2008, Johnson et al. 2008).

If we link our knowledge of a plant community's structure - and the degree of mycotrophy of plants comprising the community - with knowledge of soil resource availability, we can predict the influence of AMF on plant communities in different soil environments or under various nutrient-deposition scenarios. For example, where dominant plant species are highly mycotrophic (e.g., tallgrass prairies), the presence of AMF will depress diversity by reinforcing competitive superiority of a few species; however, this effect will be most pronounced where $\mathrm{P}$ is limiting (Fig. 1a). Where $\mathrm{P}$ is abundant, $\mathrm{AMF}$ will play a minimal role in governing plant diversity. In communities where the subordinate species benefit from AMF more than the dominants (e.g., cool-season grasslands), AMF will increase diversity; again, this effect will be most dramatic where $\mathrm{P}$ is limiting (Fig. 1b). Thus, we propose that AMF mediate plant diversity, but the influence of AMF at the community level will depend on both soil nutrient levels and plant community composition. Specifically, the influence of AMF on diversity will be strongest at low nutrient (specifically P) levels; the direction of the a) Dominant species are mycorrhizal

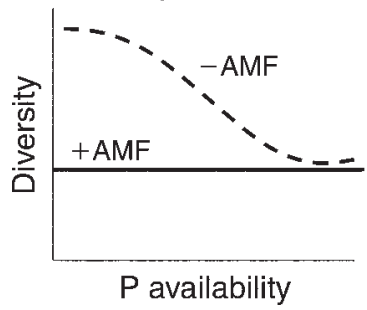

b) Subordinate species are mycorrhizal

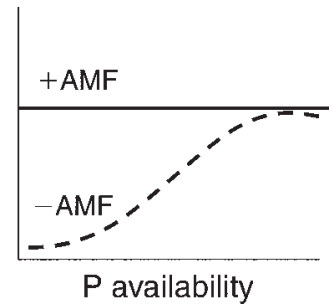

FIG. 1. Conceptual model illustrating the interactive effects of arbuscular mycorrhizal fungi (AMF) and soil nutrient levels on plant communities dominated by (a) highly mycotrophic or (b) less mycotrophic species. As phosphorus (P) becomes less available, AMF play a stronger role in mediating plant community diversity. If the plant community is dominated by highly mycotrophic species, AMF suppress diversity by enhancing growth of dominants. If the subordinate species in the community are relatively more mycotrophic, AMF enhance their growth, thereby increasing diversity. For systems in which nutrients are the primary host benefit to AMF, this model predicts that the influence of AMF on diversity will be strongest at low nutrient (specifically P) levels. Whether AMF increase or decrease diversity at low $\mathrm{P}$ depends on the relative degree of mycotrophy among plants in the community.

Note: Specific diversity values are not meant to be compared among community types (i.e., Fig. 1a vs. b); the influence of AMF across a nutrient gradient applies only within community types.

influence will depend on the relative degree of mycotrophy among plants in the community.

In this study, we explore the plant community consequences of altering the resource environment in which plants and AMF interact. We hypothesize that (1) the influence of AMF on plant diversity will depend on soil nutrient levels, (2) the influence of AMF on plant communities will be greatest in P-limited environments, and (3) shifts in community composition will result from differential responses of $\mathrm{C}_{4}$ (highly mycotrophic) and $\mathrm{C}_{3}$ (less mycotrophic) species to AMF along the soil nutrient gradient. To test these hypotheses, we devised an experiment using mesocosm communities composed of native tallgrass prairie species. By manipulating the presence and absence of AMF and soil $\mathrm{P}$, we quantified the effects of AMF on plant community diversity, composition, and productivity along a soil nutrient gradient.

\section{Methods}

This study was conducted at the University of Kansas Ecological Reserves, $20 \mathrm{~km}$ north of Lawrence, Kansas, USA. We chose a mesocosm approach because we could have strict control over nutrients and the presence/absence of AMF. Two AMF treatments (+AMF and -AMF) were combined with five nutrient treatments in a factorial design, with five replicates for each treatment combination. Initially, each mesocosm contained identical plant communities composed of nine perennial, native grass species that coexist in Kansas tallgrass 
prairies: Agropyron smithii Rydb. $\left(\mathrm{C}_{3}\right)$, Andropogon gerardii Vitman $\left(\mathrm{C}_{4}\right)$, Bouteloua curtipendula (Michx.) Torr. $\left(\mathrm{C}_{4}\right)$, Elymus canadensis L. $\left(\mathrm{C}_{3}\right)$, Hordeum jubatum L. $\left(\mathrm{C}_{3}\right)$, Koleria pyramidata (Lam.) Beauv. $\left(\mathrm{C}_{3}\right)$, Schizachyrium scoparium (Michx.) Nash $\left(\mathrm{C}_{4}\right)$, Sorgastrum nutans (L.) Nash $\left(\mathrm{C}_{4}\right)$, and Sporobolus heterolepis (A. Gray) A. Gray $\left(\mathrm{C}_{4}\right)$. We used perennial grasses because they dominate native prairies and are targeted for restoration efforts in our region. Species were selected based on frequency of occurrence in our region, functional group (five $\mathrm{C}_{4}$ grasses and four $\mathrm{C}_{3}$ grasses to maximize variability in response to $\mathrm{AMF}$ ), and availability (Stock Seed Farms, Murdock, Nebraska, USA; Critical Site Products, Prairie \& Wetland Center, Belton, Missouri, USA). Seeds were planted in trays of vermiculite during the first week of March 2007 and were allowed to germinate and grow in a greenhouse (Light: Dark, 14:10 h; $25^{\circ}: 17^{\circ} \mathrm{C}$ ) for eight weeks. Seedlings were watered daily, but no nutrient or AMF treatments were applied until mesocosm communities were assembled.

Soil inoculum for $+\mathrm{AMF}$ mesocosms was collected from a native prairie in northeast Kansas. We sieved freshly collected soil through $1-\mathrm{cm}^{2}$ hardware cloth to remove large root clumps and rocks. For the $-\mathrm{AMF}$ treatment, we autoclaved sieved field soil at $121^{\circ} \mathrm{C}$ for 60 min on two consecutive days.

Each mesocosm (38 cm in diameter, $29.5 \mathrm{~cm}$ in height) held $38 \mathrm{~L}$ of a 50:50 mixture of sand and coarse perlite (Therm-o-Rock Perlite, Hummert International, Topeka, Kansas, USA). In each mesocosm we added a $1-\mathrm{cm}-$ deep layer of field $(+\mathrm{AMF})$ or autoclaved $(-\mathrm{AMF})$ soil $10 \mathrm{~cm}$ below the substrate surface. To equalize the microbial community, we added $500 \mathrm{~mL}$ of microbial slurry to each mesocosm (Koide and $\mathrm{Li}$ 1989). We prepared the slurry by passing filtrate from the extra field soil inoculum twice through a $20-\mu \mathrm{m}$ sieve. To ensure that each mesocosm received the same amount of liquid, we added $50 \mathrm{~mL}$ of water to mesocosms containing field-soil inoculum.

Most seedlings were in the second-leaf stage $(\sim 5-7 \mathrm{~cm}$ tall) when we transplanted them from the greenhouse to mesocosms in the second week of May. Mesocosms received four individuals of each species, randomly arranged in a $6 \times 6$ grid. We replaced any seedlings that died during the first three weeks. We randomized the location of the mesocosms in an outdoor lath house-an open-sided structure with wire mesh designed to exclude large herbivores. Throughout the summer, we applied nutrient solution every three days; on the two interim days we watered each mesocosm to field capacity. Mesocosm buckets were elevated to allow for drainage and to prevent nutrient contamination among treatments.

We applied nutrients as pH-adjusted aqueous solutions. The standard recipe was an adjusted Hoagland's solution (Johnson 1993) and contained: $130 \mathrm{mg} / \mathrm{L} \mathrm{K}_{2} \mathrm{SO}_{4}$; $72 \mathrm{MgSO}_{4} ; 0.03 \mathrm{mg} / \mathrm{L} \mathrm{NaCl} ; 0.86 \mathrm{mg} / \mathrm{L} \mathrm{H}_{3} \mathrm{BO}_{3} ; 0.54 \mathrm{mg} / \mathrm{L}$
$\mathrm{MnCl}_{2} \cdot 4 \mathrm{H}_{2} 0 ; 0.07 \mathrm{mg} / \mathrm{L} \quad \mathrm{ZnSO}_{4} \cdot 7 \mathrm{H}_{2} 0 ; 0.02 \mathrm{mg} / \mathrm{L}$ $\mathrm{CuSO}_{4} \cdot 5 \mathrm{H}_{2} 0 ; 0.011 \mathrm{mg} / \mathrm{L}$ FeEDTA; $433 \mathrm{mg} / \mathrm{L} \mathrm{KNO}_{3}$; $8.4 \mathrm{mg} / \mathrm{L} \mathrm{Ca}\left(\mathrm{NO}_{3}\right)_{2} \cdot 4 \mathrm{H}_{2} 0$. The $\mathrm{pH}$ was adjusted to 6.5 with $0.1 \mathrm{~mol} / \mathrm{L} \mathrm{NaOH}$. To create a gradient in $\mathrm{P}$ availability, we calculated four levels of $\mathrm{P}$ relative to a "standard P" of $44 \mathrm{mg} / \mathrm{L} \mathrm{KH}_{2} \mathrm{PO}$. We added 0.1, 0.5, 10, or 20 times the standard $\mathrm{P}$ (hereafter denoted as $0.1 \times \mathrm{P}$, $0.5 \times \mathrm{P}, 10 \times \mathrm{P}, 20 \times \mathrm{P})$. Altering $\mathrm{P}$ necessarily changes the $\mathrm{N}: \mathrm{P}$ of the nutrient solutions because $\mathrm{N}$ was held constant for each treatment. Solutions were added to field capacity; the amount of nutrient solution (and water on interim days) was adjusted across the summer accordingly.

After 15 weeks, we clipped all aboveground biomass from each mesocosm, and sorted by species. Biomass was dried at $74^{\circ} \mathrm{C}$ for $72 \mathrm{~h}$. We recorded the mass of each species separately, summing across species in a single mesocosm to estimate aboveground net community productivity (in grams). We sampled soils from each mesocosm immediately following harvest to verify the efficacy of our AMF treatments. Tangled roots prevented us from estimating root colonization for each species. In an effort to minimize the effect of plant species on our estimates of root colonization, we analyzed roots sampled directly beneath Andropogon gerardii from each mesocosm. We cleared and stained roots following Koske and Gemma (1989) and quantified percentage colonization following Giovannetti and Mosse (1980).

Shannon diversity $\left(H^{\prime}\right)$ for plant communities was calculated in PC-Ord, version 4 (McCune and Mefford 1999). Because our mesocosms contain the same number of species (and therefore have the same value for species richness), $H^{\prime}$ reflects only the evenness (relative abundances) of species. Shannon diversity was the most appropriate measure because $H^{\prime}$ captures both richness and evenness components of diversity, both of which may be influenced by AMF and nutrients in nature. Thus, expressing diversity as $H^{\prime}$ unifies the model, our results, and other experiments that manipulate AMF. We used biomass of each species as our measure of abundance in all diversity calculations. We tested for treatment effects on diversity, biomass, proportion of total community comprised of $\mathrm{C}_{4}$ plants, and single species abundances using a balanced two-way ANOVA with AMF and nutrient levels as fixed effects. Residuals were tested for normality using the Ryan-Joiner test ( $P$ $>0.1)$ and for homogeneity of variance with Bartlett's test $(P>0.1)$. We used a one-way ANOVA to test for effects of $\mathrm{P}$ level on root colonization of root samples collected from + AMF mesocosms. To characterize plant community composition, we conducted a principalcomponents analysis (PCA) using the nine species in each community as variables. Our data do not contain zeros, nor are there nonlinear relationships associated with the environmental gradient; thus, we felt PCA was an appropriate tool for visually comparing communities in multivariate space. We statistically compared the locations of the communities in each treatment in multivariate space using PERMANOVA (Anderson 
2001, McArdle and Anderson 2001), which relies on permutation methods to compute $P$ values for distances between group centroids. We then compared the degree of dispersion among treatment communities using PERMDISP (Anderson 2004). For both permutation tests we calculated Bray-Curtis distances and used 999 permutations. Parametric statistics were performed in Minitab 14.1.

\section{RESUlTS}

Roots from mesocosms containing autoclaved soil contained either no arbuscular mycorrhizal fungi (AMF), or extremely low levels (Fig. 2). Among the field-soil-inoculated mesocosms, root colonization increased as added $\mathrm{P}$ decreased; communities receiving the least $\mathrm{P}$ (highest $\mathrm{N}: \mathrm{P}$ ) had the highest percentage colonization $\left(F_{4,20}=5.78, P=0.003\right)$. Communities with $10 \times \mathrm{P}$ and $20 \times \mathrm{P}$ did not differ from one another, but had significantly less colonization ( $20 \%$ on average) than both treatments receiving reduced amounts of $\mathrm{P}$ (Tukey simultaneous test, $P<0.05$ ).

Community structure for plant communities with and without AMF diverged as phosphorus became more limiting (Fig. 3a). Diversity at any given nutrient level depended on the presence of AMF (Fig. 3b; AMF $\times$ nutrient: $\left.F_{4,40}=4.15 ; P=0.007\right)$. AMF increased diversity where $\mathrm{P}$ was less available. By contrast, where $\mathrm{P}$ was abundant, we detected no difference in diversity between communities with and without AMF (Tukey simultaneous test, $P>0.1$.

Communities segregated in multivariate space (Fig. 4) illustrating that nutrients and AMF interact to determine community composition. The first axis of the PCA ordination (Fig. 4) represents the effect of nutrients on the biomass of species in each community ( $\mathrm{P}$ is more limiting on the right-hand side of the graph); the second PC axis reflects species' growth response to AMF. AMF strongly affected community composition, but moreso where $\mathrm{P}$ was most limiting (Fig. 4; AMF $\times$ nutrient: PERMANOVA $\left.F_{4,40}=4.02, P=0.001\right)$. This is illustrated by the greater separation of $+\mathrm{AMF}$ and -AMF plots on the right-hand side of the PCA ordination (Fig. 4). By contrast, only nutrient levels significantly influenced community dispersion (PERMDISP $F_{4,40}=4.40 P=0.007$ ), although AMF and the interaction between AMF and nutrients both influenced dispersion at the $\alpha=0.1$ significance level.

In all but one nutrient treatment, both mycorrhizal and nonmycorrhizal communities were dominated by Elymus canadensis, which contributed $31-42 \%$ of the total community biomass (Fig. 5). Neither of the two species dominant in most treatments, E. canadensis and Bouteloua curtipendula, responded significantly to AMF. Both species achieved greater biomass in soils with high $\mathrm{P}$ levels, regardless of AMF treatment (Fig. 6; $E$. canadensis, nutrient $F_{4,40}=18.06, P<0.001$; AMF $F_{1,40}=1.02, P>0.2$; AMF $\times$ nutrient $F_{4,40}=1.38, P>$ $0.2 ;$ B. curtipendula, nutrient $F_{4,40}=15.78, P<0.001$;

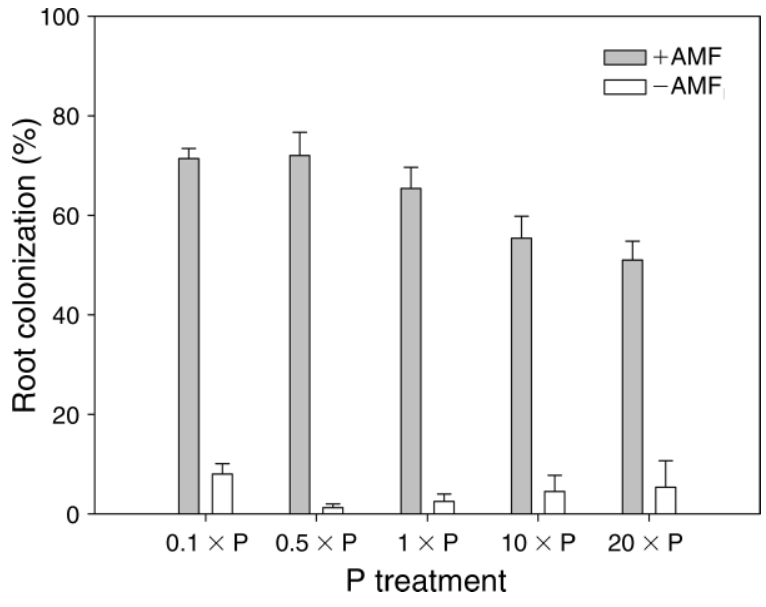

FIG. 2. Percentage colonization of roots collected from beneath Andropogon gerardii in each mesocosm, for five levels of $\mathrm{P}$ addition (where the standard $\mathrm{P}$ is $44 \mathrm{mg} / \mathrm{L} \mathrm{KH}{ }_{2} \mathrm{PO}$ ). Data are means $+\mathrm{SE}$.

AMF $F_{1,40}=0.19, P>0.2$; AMF $\times$ nutrient $F_{4,40}=2.02$, $P>0.1)$. Differences in overall community composition that we observed among nutrient and AMF treatments were manifested primarily through responses by the subordinate species, many of which responded dramatically to the presence of AMF (Figs. 5 and 6).

Although there were some species-specific differences in the degree to which AMF influenced biomass across the nutrient gradient (Fig. 6), responses were generally consistent among species within a functional group (defined by photosynthetic pathway): at low P, maximum growth for most $\mathrm{C}_{4}$ species occurred in the presences of AMF, while $C_{3}$ species performed better in the absence of AMF. Consequently, in mesocosms lacking $\mathrm{AMF}$, the proportion of the community comprised of $\mathrm{C}_{4}$ grasses declined significantly at low $\mathrm{P}$ levels $\left(\mathrm{AMF} \times\right.$ nutrient interaction: $F_{4,40}=5.90, P=$ $0.001)$.

Total community biomass increased as $\mathrm{P}$ availability increased; however, at low $\mathrm{P}$, the communities with AMF were significantly more productive than those without AMF (Fig. 7; AMF $\times$ nutrient: $F_{4,40}=4.67, P=$ $0.003)$.

\section{Discussion}

Our study demonstrates that soil nutrient levels and AMF (arbuscular mycorrhizal fungi) interact to determine prairie plant community diversity, composition and productivity. While previous work has shown that the presence, abundance, and diversity of AMF (van der Heijden [2002] and references therein), as well as AMF species identity (Klironomos 2003, Vogelsang et al. 2006) can influence plant communities, our results emphasize that contingences of resource supply may govern community-level outcomes of AMF-plant interactions. 


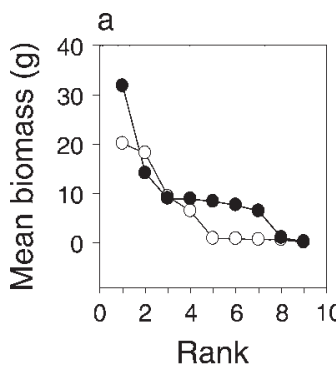

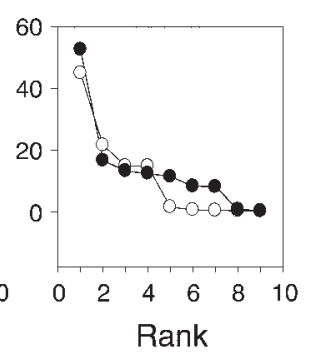

Rank

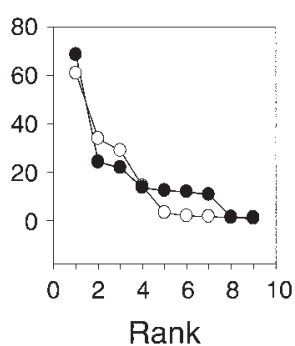

Rank

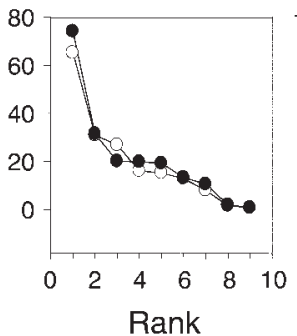

Rank

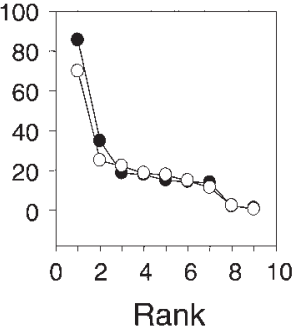

Rank

P availability

$\begin{array}{llll}0.1 \times \mathrm{P} & 0.5 \times \mathrm{P} & 1 \times \mathrm{P} & 10 \times \mathrm{P}\end{array}$

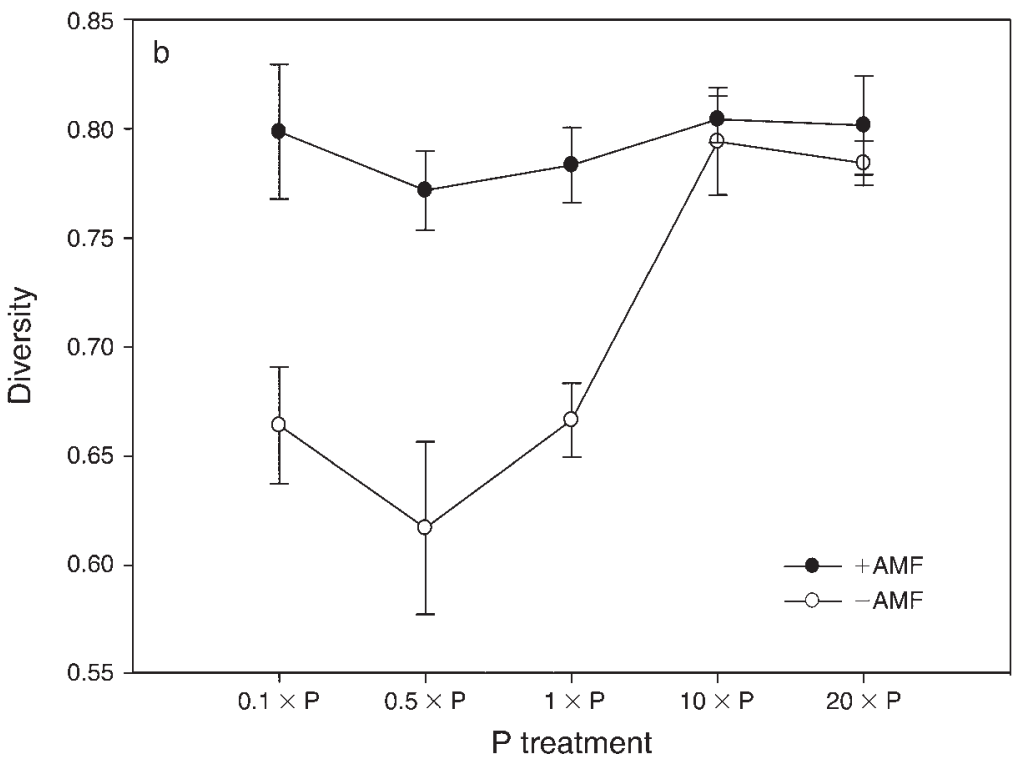

FIG. 3. (a) Community rank abundance curves for $+\mathrm{AMF}$ and $-\mathrm{AMF}$ mesocosms along a gradient from low to high $\mathrm{P}$ availability; note the different $y$-axis scales. Each point represents the mean abundance of a species (calculated from five replicate communities, with abundance measured as biomass), ranked in order of abundance relative to other species in the community. (b) Interactive effect of soil $\mathrm{P}$ and AMF (+AMF and - AMF) on plant diversity; data are means \pm SE.

At low $\mathrm{P}$ levels, we found that AMF increased diversity in our mesocosm communities. Although we used native tallgrass prairie species, our results contrast with Hartnett and Wilson's (1999) work in tallgrass prairies. They found that AMF decreases diversity and proposed that because the dominant $\mathrm{C}_{4}$ grasses are highly mycotrophic, removing AMF allowed for competitive release of the subordinate (often $\mathrm{C}_{3}$ ) species. Our results better match those obtained in the European grassland experiments in which the dominant plants were cool-season, relatively non-mycotrophic species (Grime et al. 1987, van der Heijden et al. 1998). Accordingly, in our study, Elymus canadensis $\left(\mathrm{C}_{3}\right.$ grass) dominated nearly all treatment communities, and showed no significant positive growth response to AMF. The fast growth rate of E. canadensis, paired with atypically cool spring and summer temperatures in 2007, may explain its competitive success over mycotrophic, warm-season plant species (e.g., Andropogon gerardii) that typically dominate native prairies. Regardless, our results are consistent with the general prediction that the relative mycorrhizal dependency of the dominant vs. the subordinate plants determines the direction of the community-diversity response to AMF.

Importantly, our results also demonstrate that the effect of AMF on plant communities is not uniform across soil nutrient levels (Fig. 3). Where P availability was lowest, AMF were most influential, increasing diversity and biomass relative to communities lacking AMF. When $P$ was not limiting, AMF did not influence diversity or productivity. These results are consistent with the model presented in Fig. 1b and suggest that by combining our knowledge of the relative mycotrophy of coexisting species with our knowledge of soil resource availability, we may be able to predict the influence of AMF on plant communities.

Previous models that predict the effects of AMF on plant communities have also considered soil nutrients. 


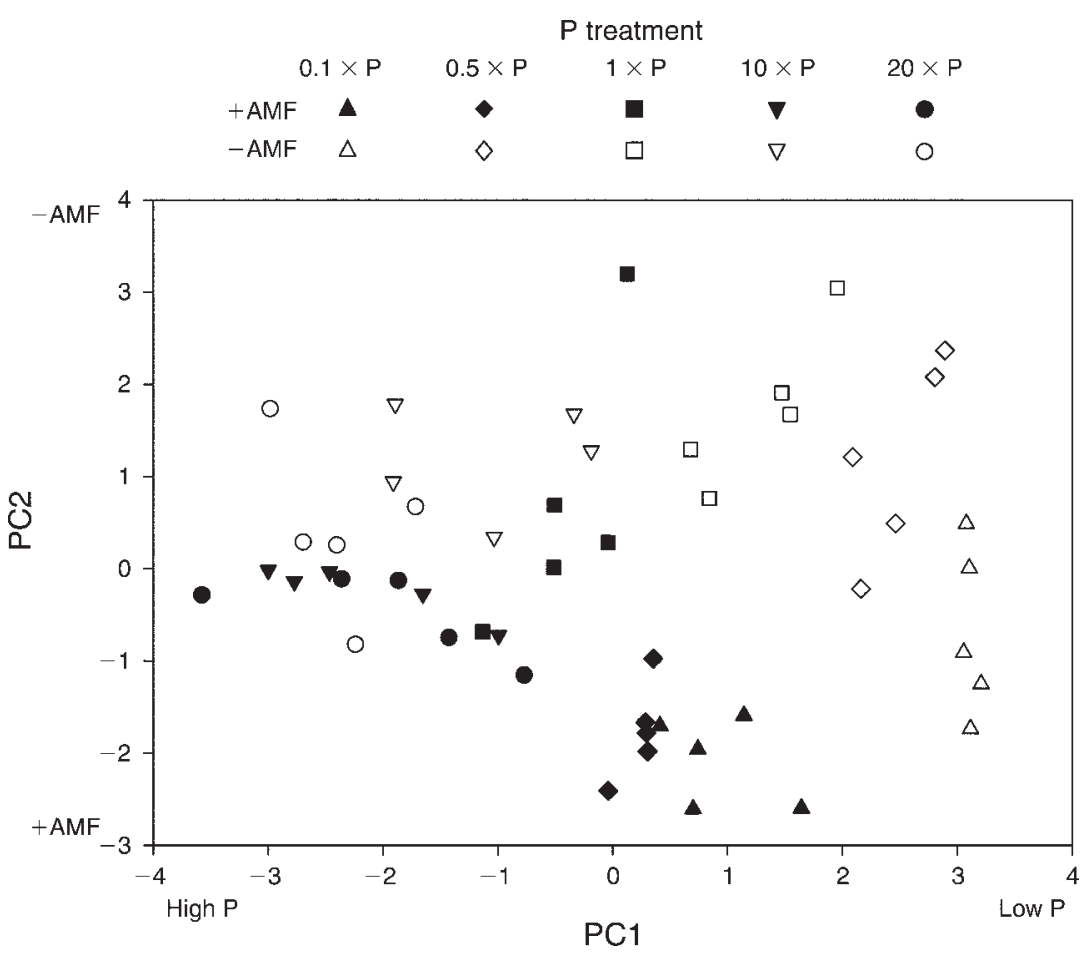

FIG. 4. Principal-components analysis for mesocosm communities comprised of nine species. Communities are coded for +AMF (solid symbols) and -AMF (open symbols) treatments, as well as nutrient treatments. AMF determined community composition most strongly where $\mathrm{P}$ was limiting $(P<0.001)$.

For example, van der Heijden (2002) presented a model based on Tilman's (1982) resource-ratio theory. He suggested that by increasing the access of host plants to $\mathrm{P}$ (presumably at the expense of $\mathrm{N}$ acquisition), AMF may increase species richness of a community. Our results are consistent with van der Heijden's model because we found that in a community in which subordinate species are mycotrophic, AMF increase diversity at low $\mathrm{P}$ (albeit through evenness and not richness). However, the resource-ratio modeling approach applies only to low-P soils in which AMF are necessary to access $\mathrm{P}$, and in communities in which

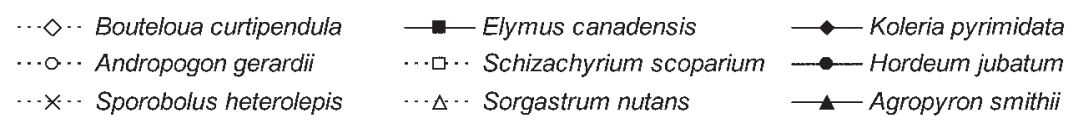

a) + AMF

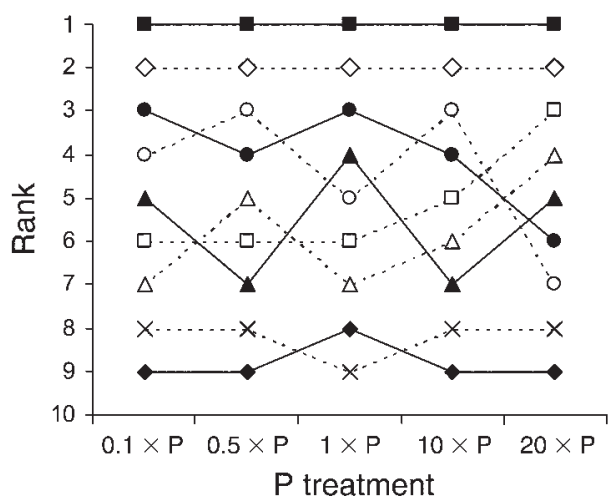

b) $-\mathrm{AMF}$

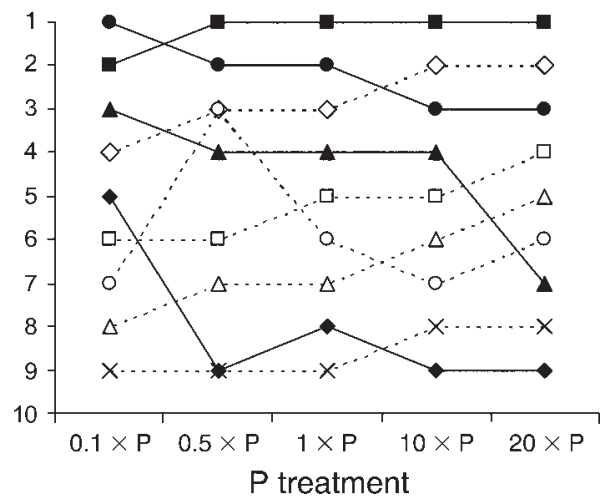

FIG. 5. Shifting ranks of each of the nine perennial native grass species within its community across the $\mathrm{P}$ gradient for both (a) $+\mathrm{AMF}$ and (b) - AMF treatments. $\mathrm{C}_{3}$ species are represented by solid symbols and solid lines; $\mathrm{C}_{4}$ species are represented by open symbols and dotted lines. Species are ranked in order of their abundance, but to ease interpretation the data are not scaled by biomass. 
$\mathrm{C}_{3}$ species
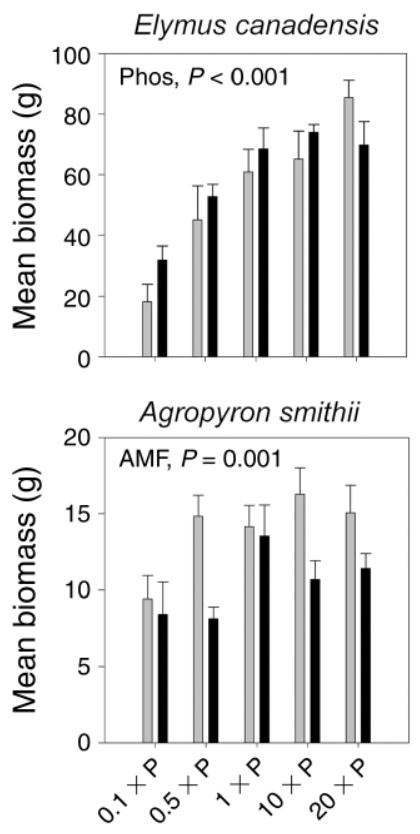

$P$ treatment
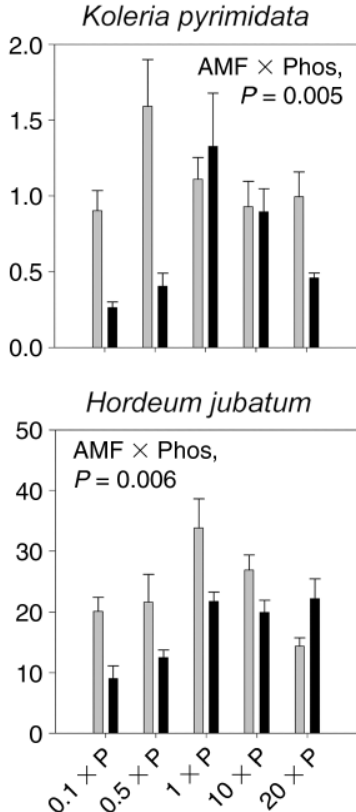

$P$ treatment
$\mathrm{C}_{4}$ species
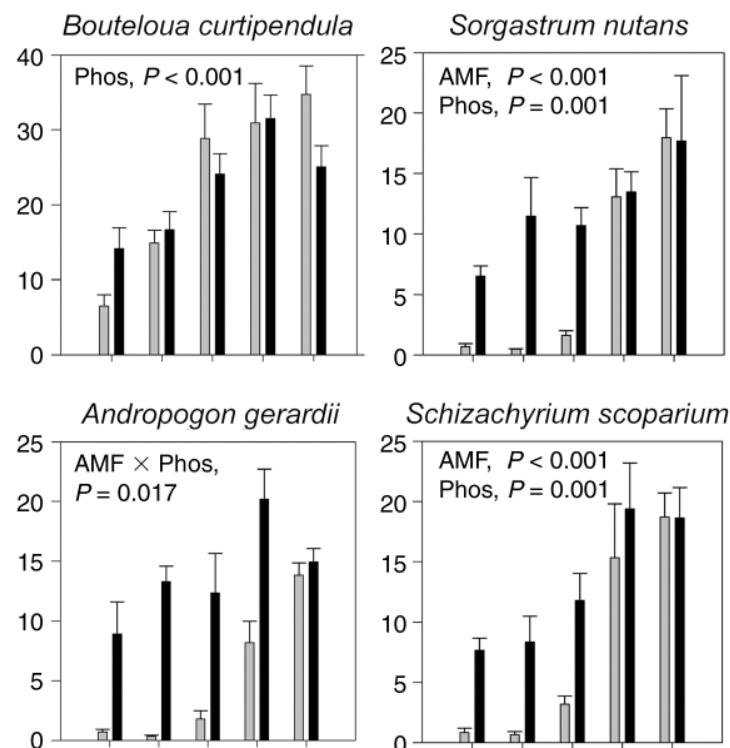

Schizachyrium scoparium

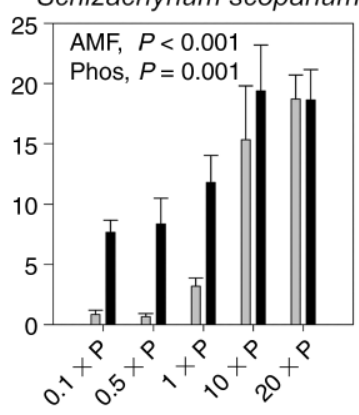

$\mathrm{P}$ treatment
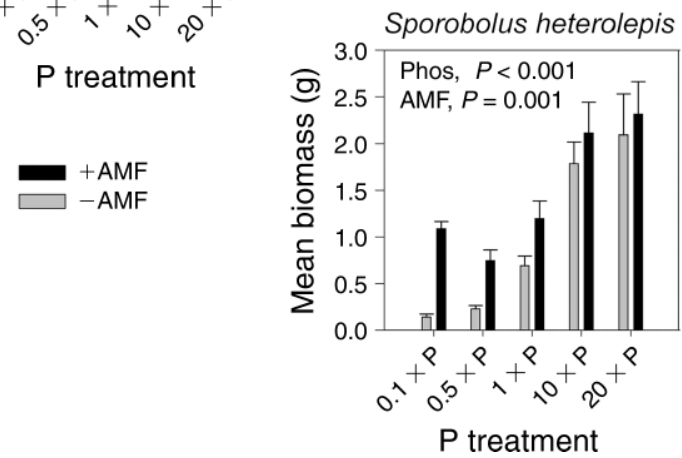

FIG. 6. Aboveground biomass for each of the nine perennial native grass species with or without AMF at each phosphorus (Phos) level. Data are means and SE. Note that values on the $y$-axes differ among graphs. $P$ values from two-way ANOVAs are presented for statistically significant results; in cases where the interaction is significant, results for main effects are not shown.

mycotrophic species do not dominate. By contrast, we provide a model that takes into account a soil nutrient gradient, as well as plant community composition, emphasizing that the role of AMF in mediating plant community diversity depends both on nutrient status and the degree of mycotrophy of the dominant species.

Because our model focuses specifically on the impact of AMF on diversity as mediated by P supply, we rely on several implicit assumptions. For instance, we assume that $\mathrm{P}$ availability does not directly influence plant diversity (i.e., through mechanisms other than via AMF). In most terrestrial systems, direct effects of $\mathrm{P}$ on diversity appear to be the exception (e.g., Goldberg and Miller 1990, Wilson et al. 1996), rather than the rule (Gough et al. 2000). Indeed, we have seen no effect of long-term $\mathrm{P}$ addition on diversity in field experiments at our site (B. L. Foster, unpublished manuscript). Still, it is worth noting that our model may not fully apply to wetland and moist systems where diversity is often sensitive to $\mathrm{P}$ additions (e.g., Wassen et al. 2005).
We also assume that parasitic effects of AMF are not strong (or consistent) enough to have community-level consequences. Our results were consistent with this assumption: even at the highest amounts of $\mathrm{P}$ added, we observed few indications of nutrient-induced parasitism, and no consistent response across functional groups was apparent. Only two species, Bouteloua curtipendula $\left(\mathrm{C}_{4}\right)$, and Koleria pyrimidata $\left(\mathrm{C}_{3}\right)$, showed significant biomass declines in the presence of AMF when $\mathrm{P}$ was plentiful (Fig. 6). Agropyron smithii $\left(\mathrm{C}_{3}\right)$ was negatively affected by AMF at all nutrient levels. Notably, violating this assumption would yield data that deviate from our model in a predictable way. If, for example, mycotrophic plants were parasitized under high-P conditions (in a community with AMF in which mycotrophic plants are subordinate), we would have expected their relative abundance to decline, and consequently diversity to decline as well. Testing our model in systems where parasitism is suspected to occur would likely be very instructive. 


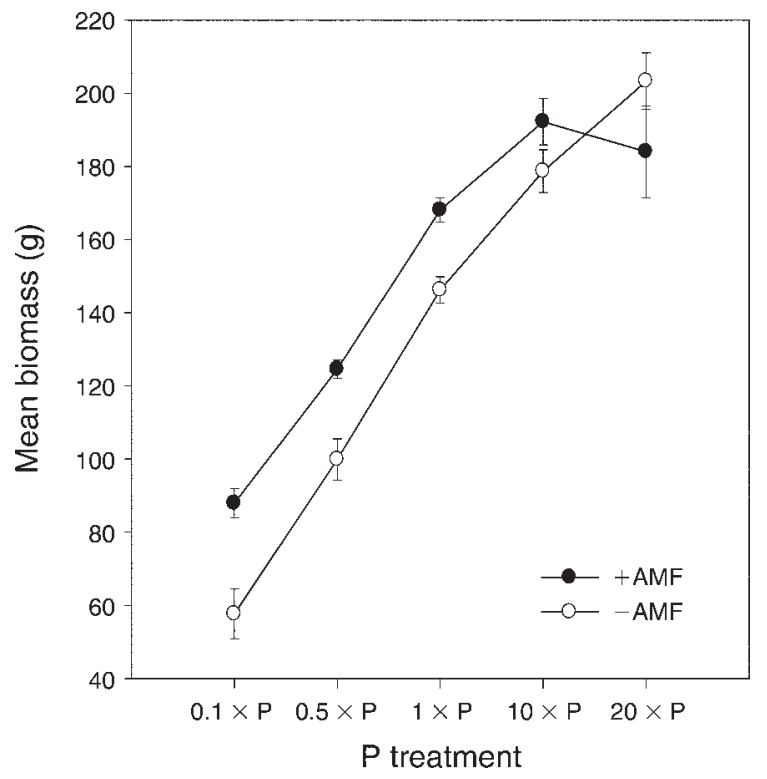

FIG. 7. Total community biomass for $+\mathrm{AMF}$ and $-\mathrm{AMF}$ mesocosms. Data are means $\pm \mathrm{SE}$. The degree to which AMF influenced biomass depended on nutrient levels: AMF increased total biomass, but only where $\mathrm{P}$ was limiting $(P<0.01)$.

The last assumption implicit in our model was that the primary benefit to plants hosting AMF is $\mathrm{P}$ acquisition. While other benefits of AMF have been documented (e.g., pathogen resistance, Newsham et al. 1995), ample evidence suggests that AMF play a prominent role in acquiring $\mathrm{P}$ in prairies (Hartnett and Wilson 2002)and, indeed, in many ecosystems (Smith and Read 1997). Moreover, we observed significant growth response in plants hosting AMF at low P levels. Still, it is possible that AMF provided additional benefits to plants in our experiment. For instance, AMF are capable of helping plants acquire N (Govindarajulu et al. 2005). If AMF increased $\mathrm{N}$ acquisition under high-P (and potentially N-limited) conditions, this could help explain the relative lack of parasitism we observed. Such functional switches by AMF along a nutrient gradient are not well documented (Reynolds et al. 2005), although Sylvia and Neal (1990) recorded increases in root colonization when plants were deficient in $\mathrm{N}$ relative to $\mathrm{P}$. In their study, $\mathrm{P}$ additions only suppressed colonization when $\mathrm{N}$ was sufficient. We also found that roots of plants in high-P treatments were colonized, but to a significantly lesser degree than at low P.

There are other possible explanations for why we did not see more evidence of parasitism. For example, we might not have added enough phosphorus to discount benefits provided by AMF. The fact that adding $20 \times \mathrm{P}$ (20 times a "standard P" of $44 \mathrm{mg} \mathrm{KH}_{2} \mathrm{PO} / \mathrm{L}$ ) did not increase biomass relative to $10 \times \mathrm{P}$ suggests that communities were saturated in $\mathrm{P}$ at the high-P end of the gradient. Still, we might not have reached the threshold of $\mathrm{P}$ (concurrent with carbon limitation) to induce parasitism. Alternatively, although root colonization is not consistently linked with growth benefits (McGonigle 1988), it is possible that the limited benefit plants derived from AMF in high-P treatments is due, at least in part, to lower colonization rates. A decline in AMF colonization may be expected if, in the presence of additional $\mathrm{P}$, plants allocate photosynthate to growth and $\mathrm{AMF}$ become $\mathrm{C}$ limited.

Because the dominant species in our experiments generally showed no response to AMF regardless of nutrient level, the differences in community structure we observed were due primarily to shifts in the relative abundance of subordinate species. Among the subordinates, a trade-off existed between the relative and absolute abundance of $\mathrm{C}_{4}$ vs. $\mathrm{C}_{3}$ species. For example, at low $\mathrm{P}$, maximum growth for most $\mathrm{C}_{4}$ species occurred in the presence of $\mathrm{AMF}$, while $\mathrm{C}_{3}$ species performed better in the absence of AMF (Fig. 6). Community composition shifted accordingly: in the absence of $\mathrm{AMF}$ at the lowest $\mathrm{P}$ levels, Hordeum jubatum $\left(\mathrm{C}_{3}\right)$ became the most dominant species, and Koleria pyrimidata $\left(\mathrm{C}_{3}\right)$ increased from being the most rare (9th) in high-P treatments to 5th most common. The ranks of Bouteloua curtipendula, Andropogon virginicus, Schizachyrium scoparium, and Sorgastrum nutans (all $\mathrm{C}_{4}$ ) declined (Fig. 5). We may have seen distinct functional-group differences in part because we attempted to minimize phenological differences in our experiment by germinating seeds in a greenhouse at the same time and providing ample water throughout the season. Timing of peak biomass production and flowering vary according to functional group, which may decrease competition in the field. Still, despite phenological differences, there remains significant overlap in the periods of growth activity of $\mathrm{C}_{3}$ and $\mathrm{C}_{4}$ plants in natural prairies (Ode et al. 1980). Field experiments in tallgrass prairie provide additional support for the role of AMF in mediating competition among functional groups in native prairies, despite phenological differences (Hartnett and Wilson 1999).

Van der Heijden et al. (2008) proposed that the significance of microbes to plant productivity will be greatest in nutrient-poor soils. Our results support this hypothesis: although in all communities biomass declined as available $\mathrm{P}$ declined, plant communities with AMF were significantly more productive relative to those without AMF at all but the highest levels of P. As we described for diversity, this result is likely reliant on whether the dominant plants are mycotrophic. It is worth noting that $\mathrm{P}$ limitation can be exacerbated by decreasing $\mathrm{P}$, as in our experiment, or by increasing $\mathrm{N}$ (e.g., Johnson et al. 2003a, 2008). The fact that in either case AMF enhances plant growth reinforces the idea that, from the plant perspective, nutrient availability is not just a matter of absolute abundance. Rather, the availability of one vital nutrient can only be understood relative to the available amounts of other key nutrients (Tilman 1982). This has important consequences for anthropogenic nutrient deposition: whether we enhance 
$\mathrm{N}$ or $\mathrm{P}$, we likely alter community productivity and AMF-mediated competitive outcomes. Regardless, the importance of absolute vs. relative abundance of nutrients for plant-fungal interactions is a research area that deserves more attention.

We detected significant effects of AMF and nutrients on biomass and diversity in only one growing season. The community dynamics we observed do not necessarily reflect equilibrium outcomes for competition among the species, nor do they reflect the influences of AMF on species richness via effects on plant recruitment (van der Heijden 2004). Rather, we may be seeing transient dynamics that are strongly influenced by differential growth rates among species (Tilman 1988). It is therefore possible that several seasons of growth may alter the competitive hierarchies we observed. However, we believe that because nutrient limitation drives competition in grasslands, and because AMF-mediated competition operates primarily via nutrient acquisition, the mechanisms driving community outcomes in our experiment are relevant regardless of the equilibrium state of the communities. Moreover, transient states may have long-lasting effects on the community via priority effects (Fukami 2004) and plant-soil feedbacks (Reynolds et al. 2003).

Our results confirm the need to identify conditional outcomes of mutualisms (Bronstein 1994) if we are to predict the influence of anthropogenic nutrient deposition on plant communities. Moreover, given the primary role of nutrient competition in prairies, restoring prairies or managing for diversity requires that we understand the influence of abiotic environments on plant-fungal symbioses and how these, in turn, influence plant diversity and productivity. Johnson et al. (2006:890) proposed a need for "... a synthesis that couples our understanding of the plant-fungus symbiosis with community- and ecosystem-level processes in a way that allows us to predict the results of mycorrhizal interactions." We believe that identifying the resource contingencies for community-level outcomes of AMF-plant interactions brings us one important step closer to achieving that goal.

\section{ACKNOWLEDGMENTS}

We thank Nancy Collins Johnson for reading a previous version of this manuscript, as well as for sharing with us her unpublished manuscript and nutrient recipe. The study was conducted at and supported by the University of Kansas Field Station and Ecological Reserves, a research unit of the Kansas Biological Survey and the University of Kansas. We thank KUKSR Small Grants Program, Kansas Native Plants Society, and NSF Grant number DEB01-08302 for funding. We also thank P. Crangle, J. McVeigh, and S. Workman for field assistance.

\section{Literature Cited}

Anderson, M. J. 2001. A new method for non-parametric multivariate analysis of variance. Austral Ecology 26:32-46.

Anderson, M. J. 2004. PERMDISP: a FORTRAN computer program for permutational analysis of multivariate dispersions (for any two-factor ANOVA design) using permutation tests. Department of Statistics, University of Auckland, Auckland, New Zealand.

Bever, J. D. 2003. Soil community feedback and the coexistence of competitors: conceptual frameworks and empirical tests. New Phytologist 157:465-473.

Bronstein, J. L. 1994. Conditional outcomes in mutualistic interactions. Trends in Ecology and Evolution 9:214-217.

Daleo, P., J. Alberti, A. Canepuccia, M. Escapa, E. Fanjul, B. R. Silliman, M. D. Bertness, and O. Iribarne. 2008. Mycorrhizal fungi determine salt-marsh plant zonation depending on nutrient supply. Journal of Ecology 96:431-437.

Foster, B. L., and K. Gross. 1998. Species richness in a successional grassland: effects of nitrogen enrichment and plant litter. Ecology 79:2593-2602.

Fukami, T. 2004. Assembly history interacts with ecosystem size to influence species diversity. Ecology 85:3234-3242.

Giovannetti, M., and B. Mosse. 1980. An evaluation of techniques for measuring vesicular-arbuscular mycorrhizal infection in roots. New Phytologist 84:489-500.

Goldberg, D. E., and T. E. Miller. 1990. Effects of different resource additions on species diversity in an annual plant community. Ecology 71:213-225.

Gough, L., C. W. Osenberg, K. L. Gross, and S. L. Collins. 2000. Fertilization effects on species density and primary productivity in herbaceous plant communities. Oikos 89:428-439.

Govindarajulu, M., P. E. Pfeffer, H. Jin, J. Abudaker, D. D. Douds, J. A. Allen, H. Bucking, P. J. Lammers, and Y. Shachar-Hill. 2005. Nitrogen transfer in the arbuscular mycorrhizal symbiosis. Nature 435:819-823.

Grime, J. P., J. M. L. Mackey, S. H. Hillier, and D. J. Read. 1987. Floristic diversity in a model system using experimental microcosms. Nature 328:420-422.

Hartnett, D. C., B. A. D. Hetrick, G. W. T. Wilson, and D. J. Gibson. 1993. Mycorrhizal influence on intraspecific and interspecific neighbor interactions among co-occurring prairie grasses. Journal of Ecology 81:787-795.

Hartnett, D. C., and G. W. T. Wilson. 1999. Mycorrhizae influence plant community structure and diversity in tallgrass prarie. Ecology 80:1187-1195.

Hartnett, D. C., and G. W. T. Wilson. 2002. The role of mycorrhizas in plant community structure and dynamics: lessons from the grasslands. Plant and Soil 244:319-331.

Janos, D. P. 1980. Mycorrhizae influence tropical succession. Biotropica 12:56-64.

Johnson, N. C. 1993. Can fertilization of soil select less mutualistic mycorrhizae? Ecological Applications 3:749-757.

Johnson, N. C., J. H. Graham, and F. A. Smith. 1997. Functioning of mycorrhizal associations along the mutualism-parasitism continuum. New Phytologist 135:575-585.

Johnson, N. C., et al. 2006. From Lilliput to Brobdingnag: extending models of mycorrhizal function across scales. BioScience 56:889-900.

Johnson, N. C., D. L. Rowland, L. Corkidi, and E. B. Allen. 2008. Plant winners and losers during grassland N-eutrophication differ in biomass allocation and mycorrhizas. Ecology 89:2868-2878.

Johnson, N. C., D. L. Rowland, L. Corkidi, L. M. EgertonWarburton, and E. B. Allen. 2003a. Nitrogen enrichment alters mycorrhizal allocation at five mesic to semiarid grasslands. Ecology 87:1895-1908.

Johnson, N. C., J. Wolf, and G. W. Koch. 2003b. Interactions among mycorrhizae, atmospheric $\mathrm{CO}_{2}$, and soil $\mathrm{N}$ impact plant community composition. Ecology Letters 6:532-540.

Klironomos, J. N. 2003. Variation in plant response to native and exotic arbuscular mycorrhizal fungi. Ecology 84:22922301.

Klironomos, J. N., J. McCune, M. Hart, and J. Neville. 2000. The influence of arbuscular mycorrhizae on the relationship between plant diversity and productivity. Ecology Letters 3: $137-141$. 
Koide, R. T. 1991. Nutrient supply, nutrient demand and plant response to mycorrhizal infection. New Phytologist 117:365386.

Koide, R. T., and M. Li. 1989. Appropriate controls for vesicular-arbuscular mycorrhiza research. New Phytologist 111:35-44.

Koske, R. E., and J. N. Gemma. 1989. A modified procedure for staining roots to detect mycorrhizas. Mycological Research 92:486-488.

McArdle, B. H., and M. J. Anderson. 2001. Fitting multivariate models to community data: a comment on distance-based redundancy analysis. Ecology 82:290-297.

McCune, B., and M. J. Mefford. 1999. Multivariate analysis of ecological data. Version 4.4. MjM Software, Gleneden Beach, California, USA.

McGonigle, T. P. 1988. A numerical analysis of published field trials with vesicular-arbuscular mycorrhizal fungi. Functional Ecology 2:473-478.

Minitab. 2003. Minitab statistical software, release 14.1. Minitab, State College, Pennsylvania, USA.

Newsham, K. K., A. H. Fitter, and A. R. Watkinson. 1995. Arbuscular mycorrhiza protect an annual grass from root pathogenic fungi in the field. Journal of Ecology 83:9911000 .

O'Connor, P. J., S. E. Smith, and F. A. Smith. 2002. Arbuscular mycorrhizas influence plant diversity and community structure in a semiarid herbland. New Phytologist 154:209-218.

Ode, D. J., L. L. Tieszen, and J. C. Lerman. 1980. The seasonal contribution of $\mathrm{C}_{3}$ and $\mathrm{C}_{4}$ plant species to primary production in a mixed prairie. Ecology 61:1304-1311.

Reynolds, H. L., A. E. Hartley, K. M. Vogelsange, J. D. Bever, and P. A. Schultz. 2005. Arbuscular mycorhizal fungi do not enhance nitrogen acquisition and growth of old-field perennials under low nitrogen supply in glasshouse culture. New Phytologist 167:869-880.

Reynolds, H. L., A. Packer, J. D. Bever, and K. Clay. 2003. Grassroots ecology: plant-microbe-soil interactions as drivers of plant community structure and dynamics. Ecology 84: 2281-2291.

Smith, S., and D. Read. 1997. Mycorrhizal symbiosis. Academic Press, London, UK.

Sylvia, D. M., and N. H. Neal. 1990. Nitrogen affects the phosphorus response of VA mycorrhiza. New Phytologist 115:303-310.

Tilman, D. 1982. Resource competition and community structure. Princeton University Press, Princeton, New Jersey, USA.

Tilman, D. 1985. The resource-ratio hypothesis of plant succession. American Naturalist 125:827-852.
Tilman, D. 1987. Secondary succession and the pattern of plant dominance along experimental nitrogen gradients. Ecological Monographs 57:189-214.

Tilman, D. 1988. Plant strategies and the dynamics and structure of plant communities. Princeton University Press, Princeton, New Jersey, USA.

Tylianakis, J. M., R. K. Didham, J. Bascompte, and D. A. Wardle. 2008. Global change and species interactions in terrestrial ecosystems. Ecology Letters 11:1351-1363.

Urcelay, C., and S. Diaz. 2003. The mycorrhizal dependence of subordinates determines the effect of arbuscular mycorrhizal fungi on plant diversity. Ecology Letters 6:388-391.

van der Hiejden, M. G. A. 2002. Arbuscular mycorrhizal fungi as a determinant of plant diversity: in search of underlying mechanisms and general principles. Pages 243-265 in M. G. A. van der Hiejden and I. R. Sanders, editors. Mycorrhizal ecology. Ecological Studies 157. SpringerVerlag, Heidelberg, Germany.

van der Hiejden, M. G. A. 2004. Arbuscular mycorrhizal fungi as support systems for seedling establishment in grassland. Ecology Letters 7:293-303.

van der Hiejden, M. G. A., R. D. Bardgett, and N. M. van Straalen. 2008. The unseen majority: soil microbes as drivers of plant diversity and productivity in terrestrial ecosystems. Ecology Letters 11:296-310.

van der Heijden, M. G. A., J. N. Klironomos, M. Ursic, P. Moutoglis, R. Streitwolf-Engel, T. Boller, A. Wiemken, and I. R. Sanders. 1998. Mycorrhizal fungal diversity determines plant biodiversity, ecosystem variability and productivity. Nature 396:69-72.

Vogelsang, K. M., H. L. Reynolds, and J. D. Bever. 2006. Mycorrhizal fungal identity and richness determine the diversity and productivity of a tallgrass prairie system. New Phytologist 172:554-562.

Wardle, D. A., R. D. Bardgett, J. N. Klironomos, H. Setala, W. H. Van der Putten, and D. H. Wall. 2004. Ecological linkages between aboveground and belowground biota. Science 304:1629-1633.

Wassen, M. J., H. O. Venterink, E. D. Lapshina, and F. Tanneberger. 2005. Endangered plants persist under phosphorus limitation. Science 437:547-550.

Wilson, G. W. T., and D. C. Hartnett. 1998. Interspecific variation in plant responses to mycorrhizal colonization in tallgrass prairie. American Journal of Botany 85:1732-1738.

Wilson, J. B., T. C. E. Wells, I. C. Trueman, G. Jones, M. D. Atkinson, M. J. Crawley, M. E. Dodds, and J. Silvertown. 1996. Are there assembly rules for plant species abundance? An investigation in relation to soil resources and successional trends. Journal of Ecology 84:527-538. 